\title{
Sorption of Iron, Manganese, and Copper from Aqueous Solution Using Orange Peel: Optimization, Isothermic, Kinetic, and Thermodynamic Studies
}

\author{
Dalibor Surovka*, Eva Pertile \\ VŠB - TU Ostrava, Faculty of Mining and Geology, \\ 17. Listopadu 15, 708 33, Ostrava - Poruba
}

Received: 14 July 2015

Accepted: 5 November 2015

\begin{abstract}
The adsorption of selected metals $(\mathrm{Cu}, \mathrm{Mn}$, and $\mathrm{Fe})$ from water solution using orange peel was studied by means of batch mechanism. The aim of this study was to determine the dependency of the sorption process on $\mathrm{pH}$ of the solution, the initial concentration of the sorbent, contact time, and temperature. The Langmuier and Freundlich isothermal models were used to describe the sorption isotherms of ions. In this case the Langmuier model is more suitable to describe the data. The adsorption efficiency of removing copper $\left(q_{20}=5 \mathrm{mg} / \mathrm{g}\right)$ and manganese $\left(q_{20}=15 \mathrm{mg} / \mathrm{g}\right)$ by using orange peel was approximately $90 \%$. Under optimal conditions, the efficiency of removing iron $\left(q_{20}=10 \mathrm{mg} / \mathrm{g}\right)$ was approximately $55 \%$. When studying the kinetics we discovered that the sorption process will follow the pseudo second-order. The thermodynamic parameters show an exothermic character of sorption, and the processes are spontaneous and favourable. The results indicate that it is possible to use orange peel effectively for removing selected metals from wastewater.
\end{abstract}

Keywords: sorption, sorption kinetics, equilibrium isotherms, thermodynamics, kinetic rate equations

\section{Introduction}

The issue of wastewater is becoming more and more important today because of the new European Union laws leading to even stricter norms. Heavy metals belong to some of the negative elements present in wastewater. Their occurrence in wastewater caused by different industrial processes, such as electroplating, metal finishing,

*e-mail: dalibor.surovka@vsb.cz metallurgy, chemical production, mining, and production of paper or batteries, raises many questions because of their toxicity even in small concentrations [1].

Sorption of heavy metals is one of the most promising technologies used for the removal of contaminants from water. It is a potential alternative to conventional procedures for its low cost, easy availability, and no nutritional requirements. Sorption minimizes the volume of chemical and/or biological sludge, which must subsequently be disposed of. It is also effective for detoxifying dilute wastewaters. Great attention has recently been paid to sorption of heavy metals from solutions using biological 
materials as adsorbents [2]. The potential use of some low-cost materials, including agricultural products and waste from fishing (such as rice husks, sawdust, peanut shells, pumpkin waste, Nypafruticans, shrimp and crab shells, chitin and chitosan) has been studied. Some of the mentioned materials showed exceptional adsorption properties [3-4].

Processed solid waste orange peel has been used as an adsorbent before. It has been verified that it has a great potential to adsorb harmful pollutants, including heavy metals. However, this study evaluates orange peel used to remove three selected metals - $\mathrm{Cu}, \mathrm{Fe}$, and $\mathrm{Mn}$ - from the water matrix, as they have not been tested so far based on the available literature. The effects of various operating parameters, such as the initial $\mathrm{pH}$ value of solution, the amount of sorbent, particle size, contact time, thermodynamics, and sorption equilibrium are observed.

\section{Material and Methods}

\section{Chemicals and Equipment}

All the used chemicals were of an analytical reagent grade. We used deionized double-distilled water throughout the experiment. Analytical-grade $\mathrm{HCl}, \mathrm{NaOH}$, and buffer solutions were used to adjust solution $\mathrm{pH}$. We used an ION 340i (WTW, Czech Republic) pH meter for $\mathrm{pH}$ measurements. The metal concentrations in the samples were determined using a DR 2800 spectrophotometer.

\section{Biomass Preparation}

Orange peel, as the biosorbent in this study, was collected from household waste from 2011 to 2012. During collection, the peel was sorted manually, freed of coarse dirt, and washed with tap water and distilled water (removal of adherent dirt and soluble components, such as tannins, resins, reducing sugar, and dyes). It was left to dry at room temperature $\left(25 \pm 2^{\circ} \mathrm{C}\right)$ and checked for possible mold.

Heat treatment preceded mechanical treatment. Drying was carried out in an oven ECOCELL (Brno Medical Technologies, Inc., MM Group, Czech Republic). The samples were dried at $65 \pm 1^{\circ} \mathrm{C}$ (higher temperatures led to sample burning). In this way, the sorbent was dried to reach constant weight.

Mechanical treatment followed and included modification of the biosorbent's grain size. The adsorption material was manually fragmented and crushed in a Raptor 624 HT6523 mobile crusher (Werco, s.r.o., Czech Republic). To achieve a finer grain size, we used a laboratory mill IKAA11 basic (IKA, Werke, Germany). Through stainless analytical sieves Retsch (RetschGmbH, Germany) the material was classified into different grain size classes. We finally selected three size fractions, namely $<0.5 \mathrm{~mm}, 0.5$ to $1 \mathrm{~mm}$, and $1-2 \mathrm{~mm}$.

To make the adsorption more effective, chemical modification of adsorbents may ensure the accessibility of the functional groups on the surface of the adsorbent. Hydrochloric acid and sodium hydroxide were selected as activating agents, each at a concentration of $1 \mathrm{~mol} / \mathrm{l}$. For each gram of the adsorbent, $20 \mathrm{ml}$ of an activating solution were used. We mixed the samples using an IKAKS 4000i control laboratory shaker (Germany) for $30 \mathrm{~min}$ at $150 \mathrm{rpm}$, namely for each particle size and for each activator. Having activated the adsorbents, they were filtered and subsequently washed with distilled water several times to remove the residual activating agent. The final $\mathrm{pH}$ was measured by an ION340i pH meter (WTW, Czech Republic). Subsequently, the activated adsorbent was dried at $65 \pm 1^{\circ} \mathrm{C}$ to constant weight in order to guarantee its exact weight to determine the equilibrium adsorption process.

\section{Preparation of Metal Ion Solution}

To study iron removal under optimal conditions, it was necessary to prepare stock iron solution at a concentration of $1,000 \mathrm{mg} / \mathrm{l}$. The model solution was prepared of diammonium-iron sulfate $\left(\mathrm{Fe}\left(\mathrm{NH}_{4}\right)_{2}\left(\mathrm{SO}_{4}\right)_{2} \cdot 6 \mathrm{H}_{2} \mathrm{O}\right)$ p.a., PENTA in a 1-litre volumetric flask, and refilled with distilled water. In the study of manganese removal, we prepared stock manganese solution at a concentration of 1,000 $\mathrm{mg} / \mathrm{l}$. The solution was prepared of potassium permanganate $\left(\mathrm{KMnO}_{4}\right.$, p.a., PENTA) in a 1-litre volumetric flask, and refilled with distilled water. In the study of copper removal, we prepared stock copper solution at a concentration of $1,000 \mathrm{mg} / \mathrm{l}$. The model solution was prepared of copper sulphate $\left(\mathrm{CuSO}_{4}\right.$, p.a., PENTA), in a 1-litre volumetric flask, and refilled with distilled water. The working solutions were prepared from the stock solutions having diluted them to appropriate volumes.

\section{Results and Discussion}

\section{Kinetics of Adsorption}

The adsorption kinetics are used to determine the best exposure time and time for equilibration. In order to design the ideal adsorption mechanism, it is important to first select the ideal conditions by means of the following variables, i.e., the choice of a suitable activating agent $(\mathrm{HCl}$ or $\mathrm{NaOH}$ ), the concentration of the biosorbents, particle size, the number of revolutions, temperature, and $\mathrm{pH}$ value. Each condition was studied separately. The best results obtained by these experiments were then used to study the equilibrium model. From the measured values, adsorption capacity $q$ was then calculated according to the following equation (Eq. 1) [5]:

$$
q=\frac{\left(C_{i}-C_{f}\right) \cdot V}{S}
$$

...where $q$ is the amount of the contaminant sorbed at equilibrium $(\mathrm{mg} / \mathrm{g}), V$ is the volume of the adsorbate solution (1), $C_{i}$ is the initial concentration of the adsorbate 
in the solution $(\mathrm{mg} / \mathrm{l}), C_{f}$ is the final concentration of the adsorbate in the solution ( $\mathrm{mg} / \mathrm{l})$, and $S$ is the amount of the adsorbent added to the solution of $(\mathrm{g})$.

In order to study the adsorption kinetics, the kinetic parameters of the adsorption process were also studied. The measured results were examined by Lagergren equation (Eq. 2), which represents the kinetic equation of the pseudo first-order [6-7]:

$$
\ln \left(q_{1}-q_{t}\right)=\ln \left(q_{1}\right)-k_{1} \cdot t
$$

...where $q$ is the amount of the contaminant sorbed at equilibrium $(\mathrm{mg} / \mathrm{g}), q_{t}$ is the amount of the adsorbate adsorbed in time $(\mathrm{mg} / \mathrm{g}), t(\mathrm{~h})$ is the function of time, and $k_{1}$ is the adsorption rate constant of the reaction of the pseudo first-order $(1 / \mathrm{h})$.

The kinetic equation (Eq. 3) of the pseudo secondorder is more frequently used for biosorption data analysis, and it is expressed as:

$$
\frac{t}{q_{t}}=\frac{1}{k_{2} q_{2}^{2^{2}}}+\frac{t}{q_{2}}
$$

...where $q$ is the amount of the contaminant sorbed at equilibrium $(\mathrm{mg} / \mathrm{g}), q_{t}$ is the amount of the adsorbate adsorbed in time $(\mathrm{mg} / \mathrm{g})$, and $k$, is the rate constant of the equation of the pseudo second-order $(\mathrm{g} / \mathrm{mg} \mathrm{h})$ [6-7]. The values of $k, q$, and the correlation coefficients are given in Table 1.

The model of the pseudo second-order is based on the assumption that the rate-limiting step for adsorption may be a combination of various mechanisms that describe the whole course of the adsorption as opposed to the model of the pseudo first-order. The experimental results support the assumption in which the limiting factor is the rate of the adsorption of contaminants by the physical adsorption, but which will not be the only mechanism in the biosorption process. Another mechanism may be chemisorption, which involves valence forces through the exchange of electrons between the adsorbent and adsorbate. In contrast to the model of the pseudo first-order, this model

Table 1. Kinetic parameters for the adsorption of iron, manganese, and copper at temperature $298 \mathrm{~K}$.

\begin{tabular}{|c|c|c|c|c|c|c|}
\hline & \multicolumn{3}{|c|}{ Pseudo first-order } & \multicolumn{3}{|c|}{ Pseudo second-order } \\
\hline $\begin{array}{c}\mathrm{q}_{\text {exp }} \\
\mathrm{mg} / \mathrm{g}\end{array}$ & $\begin{array}{c}\mathrm{q}_{1} \\
\mathrm{mg} / \mathrm{g}\end{array}$ & $\begin{array}{c}\mathrm{k}_{1} \\
1 / \mathrm{h}\end{array}$ & $\mathrm{R}^{2}$ & $\begin{array}{c}\mathrm{q}_{2} \\
\mathrm{mg} / \mathrm{g}\end{array}$ & $\begin{array}{c}\mathrm{k}_{2} \\
\mathrm{~g} / \mathrm{mg} \mathrm{h}\end{array}$ & $\mathrm{R}^{2}$ \\
\hline & \multicolumn{6}{|c|}{ Iron } \\
\hline 13.30 & 8.24 & 0.001 & 0.032 & 13.44 & 0.068 & 0.996 \\
\hline & \multicolumn{7}{|c|}{ Manganese } \\
\hline 5.71 & 1.33 & 0.0008 & 0.339 & 5.69 & 0.17 & 0.972 \\
\hline & \multicolumn{7}{|c|}{ Copper } \\
\hline 4.55 & 1.43 & 0.004 & 0.765 & 4.23 & 1.50 & 0.985 \\
\hline
\end{tabular}

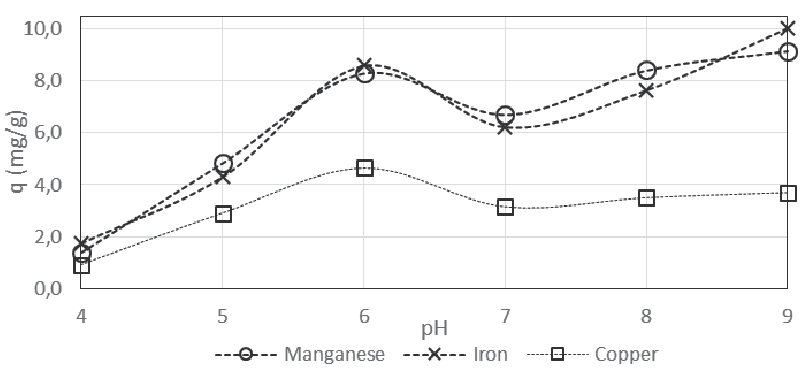

Fig. 1. Effect of $\mathrm{pH}$ on adsorption of iron, manganese, and copper.

adequately predicts the behaviour of the adsorption during the entire adsorption process. Also within the experiments, the equilibrium adsorption capacity $q$ obtained using this model was much better than the capacity obtained using the pseudo first-order model.

\section{Effect of $\mathrm{pH}$}

The influence of $\mathrm{pH}$ is the most important parameter for the process of sorption. For the removal of metals we used the $\mathrm{pH}$ of the solution between 4.0 and 8.0. A higher $\mathrm{pH}$ value is inappropriate due to the formation of precipitates because of an excess of $\mathrm{OH}^{-}$ions (Fig. 1). The contact time was chosen in accordance with the shortest exposure period and the highest removal efficiency of the adsorbate.

Table 2 shows that the adjustment of the $\mathrm{pH}$ value positively affects the sorption process. At $\mathrm{pH}=6.0$, the maximum achieved percentage of the contaminant removal from the solution almost always reached 90-100\%. For comparison we selected $\mathrm{pH}=4.0$, which already resulted in low sorption capacity. At higher $\mathrm{pH}$ values, precipitation in the form of hydroxides occurred (therefore the results are not included in the table).

\section{Thermodynamic Parameters}

In order to better understand the effect of temperature on adsorption, it is important to study such thermodynamic parameters as standard Gibbs free energy change $\left(\Delta G^{\circ}\right)$, standard enthalpy change $\left(\Delta H^{\circ}\right)$, and standard entropy change $\left(\Delta S^{\circ}\right)[8-9]$.

The plot of $\ln K_{\mathrm{c}}$ versus $1 / T$ should be linear. $\Delta H^{\circ}$ and $\Delta S^{\circ}$ were computed from the slope and intercept of van't Hoff plots of $\ln K_{\mathrm{c}}$ versus $1 / T$. The results for metal sorption onto orange peel are given in Table 3.

The calculated negative values of the Gibbs free energy for orange peel with the study of thermodynamics for individual sorbates, in whole studied temperature range, demonstrate the feasibility and spontaneity of the process. Adsorption processes with $\Delta G^{\circ}$ values ranging from -20 to $0 \mathrm{~kJ} / \mathrm{mol}$ correspond to the physical monolayer adsorption [10-11]. The obtained results show that this will be the case of monolayer adsorption in all studied cases. A spontaneous process usually corresponds to an increase of the positive value of the entropy change, 
Table 2. Effect of $\mathrm{pH}$ on adsorption of metals onto orange peel.

\begin{tabular}{|c|c|c|c|c|c|}
\hline \multirow{2}{*}{ Contaminant } & \multirow{2}{*}{$\begin{array}{c}\text { Initial concentration } \\
\mathrm{mg} / 1\end{array}$} & \multicolumn{2}{|c|}{$\mathrm{pH}=4.0$} & \multicolumn{2}{|c|}{$\mathrm{pH}=6.0$} \\
\cline { 3 - 6 } & 300 & $\begin{array}{c}q_{20} \\
\mathrm{mg} / \mathrm{g}\end{array}$ & Efficiency percentage & $\begin{array}{c}q_{20} \\
\mathrm{mg} / \mathrm{g}\end{array}$ & Efficiency percentage \\
\hline Manganese & 200 & 1.05 & 34 & 14.35 & 96 \\
\hline Iron & 100 & 0.90 & 11 & 9.30 & 93 \\
\hline Copper & & 18 & 4.65 & 93 \\
\hline
\end{tabular}

Table 3. Thermodynamic parameters for metals adsorption onto orange peel.

\begin{tabular}{|c|c|c|c|c|c|c|c|c|c|}
\hline & \multicolumn{3}{|c|}{ Iron } & \multicolumn{3}{c|}{ Manganese } & \multicolumn{3}{c|}{ Copper } \\
\hline Temperature K & 298.15 & 308.15 & 318.15 & 298.15 & 308.15 & 318.15 & 298.15 & 308.15 & 318.15 \\
\hline$\Delta G^{o} \mathrm{~kJ} / \mathrm{mol}$ & -2.74 & -2.54 & -0.53 & -3.55 & -3.44 & -1.92 & -5.97 & -0.59 & -0.45 \\
\hline$\Delta H^{\circ} \mathrm{kJ} / \mathrm{mol}$ & \multicolumn{3}{|c|}{-42} & & -44 & \multicolumn{3}{|c|}{-23} \\
\hline$\Delta S^{o} \mathrm{~J} / \mathrm{mol} \mathrm{K}$ & 8.44 & 8.12 & 1.75 & 11.36 & 11.30 & 6.56 & 20.36 & 1.88 & 1.51 \\
\hline
\end{tabular}

which was confirmed by research. A decrease in Gibbs free energy along with an increase in the temperature is probably caused by a smaller amount of active sites on the surface of the adsorbent, or there is an increase in the contaminant's mobility in an aqueous medium at an elevated temperature. Other authors have also come to the same conclusion [12-13]. The negative enthalpy value suggests that sorption will have an exothermic character over the studied range.

\section{Sorption Isotherms}

Two models were used to describe the isotherms: Langmuier and Freundlich. Both models in linearized forms are necessary to determine the values of the constants, and non-linear models were used to determine the correlation of theoretical and experimental data. Table 4 shows an overview of the linear and nonlinear models of isotherms.

The Langmuier adsorption isotherm was originally developed to describe the adsorption system gas-solid phase on activated carbon. Traditionally, it is used to quantify the diversity and performance of the individual sorbents. The linearized form (Eq. 4) goes as follows:

$$
\frac{C_{f}}{q}=\frac{1}{q_{\max }} \cdot C_{f}+\frac{1}{q_{\max } \cdot b}
$$

... where $q$ is the amount of the contaminant sorbed at the equilibrium $(\mathrm{mg} / \mathrm{g}), C_{f}$ is the final concentration of the sorbate in the solution $(\mathrm{mg} / \mathrm{l}), q_{\max }$ is the maximum adsorption amount per unit of the weight of the sorbent (which forms a complete monolayer on the surface), and $b$ is the constant relating to the affinity of the binding sites $(1 / \mathrm{mg})$ [15-16].

Experimental values of $C_{f}$ and $q$ and their mutual agreement with the theoretical value of the model is determined using the non-linear Langmuir isotherm calculated using Eq. 5 [17]:

$$
q=\frac{q_{\max } \cdot b \cdot C_{f}}{1+b \cdot C_{f}}
$$

The significance of the parameters is the same as in the previous relationships.

The Freundlich isotherm is a more commonly known relationship to describe the non-ideal and reversible adsorptions. This means that it may form multiple layers on the surface of the sorbent. This empirical model can

Table 4. Overview of linear and nonlinear equations of the used isotherms [14].

\begin{tabular}{|cccc|}
\hline Isotherm & Non-linear form & Linear form & Curve \\
\hline Langmuier & $q=\frac{q_{\max } \cdot b \cdot C_{f}}{1+b \cdot C_{f}}$ & $\frac{C_{f}}{q}=\frac{1}{q_{\max }} \cdot C_{f}+\frac{1}{q_{\max } \cdot b}$ & $\ln (\mathrm{q})$ vs. $\operatorname{Ln}\left(\mathrm{C}_{\mathrm{f}}\right)$ \\
\hline Freundlich & $q=K_{f} \cdot C_{f}^{\frac{1}{n}}$ & $\ln (\mathrm{q})=\ln K_{f}+\frac{1}{n} \cdot \ln \left(C_{f}\right)$ & $\mathrm{C}_{\mathrm{f}} / \mathrm{q}$ vs. $\mathrm{C}_{\mathrm{f}}$ \\
\hline
\end{tabular}


be applied to a multi-layer adsorption, with uneven distribution of adsorption heat and affinity for an uneven surface [18]. The linearized form (Eq. 6) of the Freundlich model can be written as follows:

$$
\ln (\mathrm{q})=\ln K_{f}+\frac{1}{n} \cdot \ln \left(C_{f}\right)
$$

...where $q$ is adsorption capacity $(\mathrm{mg} / \mathrm{g}), K_{F}$ is the Freundlich constant $\left(\mathrm{mg}^{1-(1 / \mathrm{n})} \mathbf{1}^{1 / \mathrm{n}} \mathrm{g}^{-1}\right), C_{f}$ is the final concentration of the sorbate in the solution (mg/l), and $n$ is the constant of the intensity of the adsorption [8].

To study the nonlinear coefficients of the Freundlich isotherm, Eq. 7 is used:

$$
q=K_{f} \cdot C_{f}^{\frac{1}{n}}
$$

The favourable nature of the adsorption can be expressed in terms of the dimensionless equilibrium parameter $R_{L}$ (Eq. 8). The $\mathrm{R}_{\mathrm{L}}$ parameter equation goes as follows:

$$
R_{L}=\frac{1}{1+b \cdot C_{i}}
$$

...where $b$ is the Langmuier constant $(1 / \mathrm{mg})$ and $C_{i}$ is the initial concentration of the adsorbate in the solution $(\mathrm{mg} / \mathrm{l})$ [8].

A comparison of the measured and calculated Langmuier and Freundlich constants is shown in Table 5.

The measured results showed that the removal of contaminants decreased with an increase in the initial concentration, which indicates that biosorbents only have a limited number of free sites. The value of the maximum adsorption capacity $q_{\max }$ may also be characterized as the total number of binding sites that are available for sorption. Experimental data obtained within the study of the adsorption equilibrium were well describable by the Langmuier linear model and they were in very good consensus with the calculated values. The highest value of the maximum adsorption capacity $\left(\mathrm{q}_{\max }=11.65 \mathrm{mg} / \mathrm{g}\right)$ was

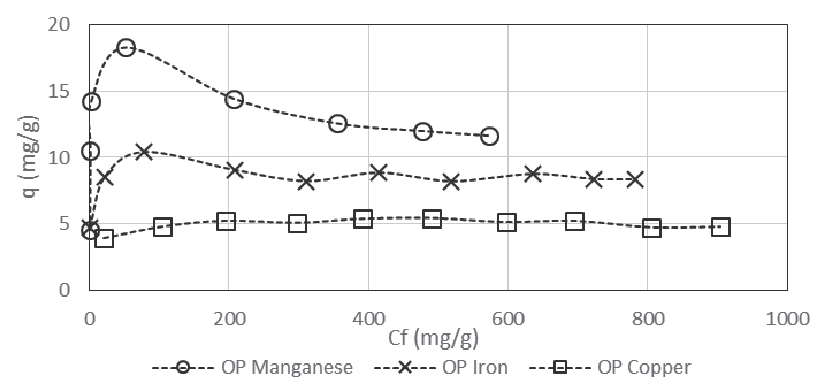

Fig. 2. Non-linear Langmuir adsorption isotherm sorption metals onto orange peel.

calculated using the Langmuier model for the removal of manganese, and the lowest value was measured in the adsorption of copper $\left(\mathrm{q}_{\max }=4.80 \mathrm{mg} / \mathrm{g}\right)$. For the removal of iron, maximum adsorption capacity $\mathrm{q}_{\max }=8.35 \mathrm{mg} / \mathrm{g}$ was calculated using the Langmuier model. The lower values of $\mathrm{R}^{2}$ show a low degree of fitness for the Freundlich isotherm on the experimental data, for all metals.

Fig. 2. showing the Langmuier non-linear adsorption isotherms, implies that in orange peel used as sorbent, the curves of the adsorption course for copper are less satisfactory - even if the adsorbent is capable of removing copper in a wide range of concentrations (up to $900 \mathrm{mg} / \mathrm{l}$ ). The adsorption curve of iron chemically modified by orange peel has a smooth course at low concentrations; at higher concentrations it leads to the depletion of adsorption sites. It may thus be concluded that the biosorbent is useful in the adsorption of iron at lower concentrations (up to $100 \mathrm{mg} / \mathrm{l}$ ). The manganese adsorption curve is steep for the biosorbents used. At higher concentrations there is a rapid depletion of available sorption sites.

Using the non-linear Langmuir adsorption isotherm, it can be concluded that the adsorbent is best applicable at lower concentrations (up to $200 \mathrm{mg} / \mathrm{l}$ of the contaminant), when there was a higher adsorption capacity than predicted by the theoretical model. This is important in the application of the adsorbent on the residual concentrations of the adsorbate, for example the final purification of wastewater. Orange peel is applicable

Table 5. All isotherm parameters of metal sorption onto orange peel.

\begin{tabular}{|c|c|c|c|c|}
\hline Isotherm model & Parameters & Iron & Manganese & Copper \\
\hline \multirow{5}{*}{ Langmuier } & $\mathrm{q}_{\max }(\mathrm{mg} / \mathrm{g})$ & 8.35 & 15.95 & 4.80 \\
\cline { 2 - 5 } & $\mathrm{q}(\mathrm{mg} / \mathrm{g})$ & 8.28 & 15.67 & 0.06 \\
\cline { 2 - 5 } & $\mathrm{b}(1 / \mathrm{mg})$ & 0.15 & 0.1 & 0.14 \\
\cline { 2 - 5 } & $\mathrm{R}_{\mathrm{L}}$ & 0.1 & 0.07 & 0.993 \\
\hline \multirow{5}{*}{ Freundlich } & $\mathrm{R}^{2}$ & 0.998 & 0.998 & 4.33 \\
\cline { 2 - 5 } & $\mathrm{q}(\mathrm{mg} / \mathrm{g})$ & 8.17 & 7.95 & 4.37 \\
\cline { 2 - 5 } & $\mathrm{K}_{\mathrm{f}}(\mathrm{mg} / \mathrm{g})$ & 4.97 & 10.79 & 3.11 \\
\cline { 2 - 5 } & $\mathrm{n}$ & 10.67 & 0.531 & 0.882 \\
\hline
\end{tabular}


at removing contaminants throughout the studied concentration range.

\section{Conclusions}

There is a constant need to develop new sorbents that are not only efficient but also cost-effective, suitable for industrial use, and environmentally friendly. The present study focused on using modified orange peel as an adsorbent for the removal of iron, manganese, and copper from aqueous medium. Adsorbent preparation, modification, characterization, and their uses for iron, manganese, and copper removal at different operating conditions are listed as well. Surface-modified orange peel showed higher efficiency than that of surfactantunmodified peel. Maximum adsorption took place at $\mathrm{pH}$ 6.0. The adsorption of iron, manganese, and copper from aqueous solution by modified orange peel will follow the Langmuir model. For the description of the experimental data, it is preferable to use the pseudo second-order model. The data indicate that the process of adsorption will be involved in a variety of mechanisms (physical adsorption and chemisorption).

Negative value of the Gibbs free energy $\Delta G^{\circ}$ was calculated for all contaminants, which implies that the adsorption process will take place spontaneously and the adsorption will be feasible. The spontaneous process is also confirmed by increasing entropy $\Delta \mathrm{S}^{\circ}$. Because the Gibbs free energy was between 0 and $-20 \mathrm{~kJ} / \mathrm{mol}$, the adsorption took place on one layer. The negative value of enthalpy $\Delta \mathrm{H}^{\circ}$ was always negative and it shows an exothermic nature of the adsorption process. This fundamental study will be helpful for further designing an orange peel adsorber for the treatment of effluents containing the iron, manganese, and copper produced by various industries.

\section{References}

1. ŠPALDON T., VIDLÁŘ J., HEVIÁNKOVÁ S. The potential of eliminating of sulphates from mine water. In: Actamontanistica Slovaca. Košice: Technická univerzita [Košice]., 1996-, 406-409. 9 (2004), 4. ISSN 1335-1788 [in Slovak].

2. FENG B., NINGCHUAN, GUO X., LIANGA S., ZHUB Y., LIUB J. Biosorption of heavy metals from aqueous solutions by chemically modified orange peel. In: Journal of Hazardous Materials. January Volume 185 (1), 49, 2011 DOI: 10.1016/j. jhazmat.2010.

3. KAMARIA A. W.S., WAN NGAHB. Isotherm, kinetic and thermodynamic studies of lead and copper uptake by $\mathrm{H}_{2} \mathrm{SO}_{4}$ modified chitosan. In: Colloids and Surfaces B: Biointerfaces. October, -266. 73 (2), 257, 2009. ISSN 0927-7765. DOI: 10.1016/j.colsurfb.2009.

4. VIJAYARAGHAVAN, YEOUNG-SANG YUN. Bacterial biosorbents and biosorption. Biotechnology Advances. 26 (3), 266, 2008 DOI: 10.1016/j.biotechadv.2008.02.002

5. CALISKAN N., KUL A.R., ALKAN S., GOKIRMAK E., SOGUT İ. ALACABEY. Adsorption of Zinc(II) on diatomite and manganese-oxide-modified diatomite: A kinetic and equilibrium study, Journal of Hazardous Materials, 193, 27, 15 October 2011.

6. YOUSEF RUSHDI I., EL-ESWED BASSAM, ALMUHTASEB ALA'A H. Adsorption characteristics of natural zeolites as solid adsorbents for phenol removal from aqueous solutions: Kinetics, mechanism, and thermodynamics studies. Chemical Engineering Journal. 171 (3), 1143, 2011 DOI: 10.1016/j.cej.2011.05.012.

7. AMEED B.H., MAHMOUD D.K., AHMAD A.L. Equilibrium modeling and kinetic studies on the adsorption of basic dye by a low-cost adsorbent: Coconut (Cocosnucifera) bunch waste. Journal of Hazardous Materials. 158 (1), 65, 2008 DOI: 10.1016/j.jhazmat.2008.01.034.

8. YS HO. Isotherms for the sorption of lead onto peat: Comparison of linear and non-linear methods. Polish Journal of Environmental Studies. Olsztyn, Poland: HARD, 1992, 15, 81, 2006 ISSN 1230-1485.

9. MUSZYŃSKI P., BRODOWSKA M.S. Effects of Potassium, Ammonium, and Calcium Chlorides on the Sorption of Metamitron in Soil. Polish journal of environmental studies. Olsztyn, Poland: HARD, 1992, 6, 2125, 2014 ISSN 12301485.

10. FERNANDES A.N., CARLOS ALBERTO POLICIANO ALMEIDA, NITO ANGELO DEBACHER A MARIA MARTA DE SOUZA SIERRA. Isotherm and thermodynamic data of adsorption of methylene blue from aqueous solution onto peat. Journal of Molecular Structure. 982 (1-3), 62, 2010 DOI: 10.1016/j.molstruc.2010.08.006.

11. VIJAYARAGHAVAN K., HENG YUN NI WINNIE, R. BALASUBRAMANIAN, MARIA MARTA DE SOUZA SIERRA, YONG WAN, LIANG CHEN, HANJUN GUO, ZHE CAO, LIXIA YANG, JUELIANG CHEN. QIANG XI. Isotherm and thermodynamic data of adsorption of methylene blue from aqueous solution onto peat. Desalination. 266 (1-3), 195, 2011 DOI: 10.1016/j.desal.2010.08.026.

12. DOULA M.K. Removal of $\mathrm{Mn}^{2}$ ions from drinking water by using Clinoptilolite and a Clinoptilolite-Fe oxide system. Water Research. 40 (17), 2006 DOI: 10.1016/j.watres.2006.07.013.

13. NCIBI M.C. Applicability of some statistical tools to predict optimum adsorption isotherm after linear and non-linear regression analysis, Journal of Hazardous Materials. 153, 207, 2008.

14. HAMDAOUI O., NAFFRECHOUX E., YAGMUR TUNALI, M. YAKUP ARICA, CHARLES WINDSON ISIDORO HAMINIUK, RAFAEL CASTOLDI, ADELAR BRACHT, ROSANE MARINA PERALTA. Modeling of adsorption isotherms of phenol and chlorophenols onto granular activated carbon Part I. Two-parameter models and equations allowing determination of thermodynamic parameters. Journal of Hazardous Materials. 147 (1-2), 381, 2007 DOI: 10.1016/j. jhazmat.2007.01.021.

15. LANGMUIR I., The constitution and fundamental properties of solids and liquids, Journal of the American Chemical Society. 38 (11), 2221, 1916.

16. SUBRAMANYAM B.M.E., DAS A. Linearized and nonlinearized isotherm models comparative study on adsorption of aqueous phenol solution in soil. International Journal of Environmental science and Technology. Article 14, 6 (4), 633, Autumn 2009.

17. Variation of Surface Coverage with Temperature \& Pressure [online]. London, 2011. Available at http://www. chem.qmul.ac.uk/surfaces/scc/scat3 4.htm

18. PUNRATTANASIN P., SARIEM P. Adsorption of $\mathrm{Cu}$, $\mathrm{Zn}$ and Ni Using Loess as Adsorbent. Polish Journal of Environmental Studies. Olsztyn, Poland: HARD, 24 (6), 2015. DOI: 10.15244/pjoes/30264. ISSN 1230-1485. 